\title{
Metabolic Syndrome and Menopause are correlated in Moroccan women population.
}

\author{
Otmane El Brini ${ }^{1}$, Omar Akhouayri ${ }^{1}$ and Bouchra Benazzouz $^{1^{*}}$. \\ ${ }^{1}$ Laboratory of Biology and Health. Ibn Tofail University - Kenitra. Morocco.
}

\begin{abstract}
:
Background: Metabolic syndrome is a cluster of metabolic risk factors for type 2 diabetes mellitus and cardiovascular diseases. Physiological variations occurring in women during menopause are thought to be a predisposing factor for the metabolic syndrome. The aim of this study was to evaluate the prevalence of metabolic syndrome and its individual components according to menopausal status in a sample of Moroccan women.

Methods: We analyzed data of 653 women aged 19 years and older. We used the recently published joint interim statement criteria to classify subjects as having metabolic syndrome.

Results: Out of the total subjects, 262 (40.12\%) were syndromic. The metabolic syndrome and abdominal obesity were more common in postmenopausal than in premenopausal women. The highest prevalence of metabolic syndrome was observed in menopausal transition especially among women aged 49-52 years (62.59\%). During this period, half of women have at least three metabolic syndrome risk factors.

Conclusion: Abdominal obesity associated with metabolic changes occurring in menopause was a risk factor for the development of metabolic syndrome in women. There is a need to adopt a healthy lifestyle to prevent weight gain in women. This can minimize the incidence of metabolic syndrome and its consequences as type 2 diabetes and cardiovascular diseases.

Keywords: Metabolic syndrome, Postmenopausal, Premenopausal, Abdominal Obesity, Menopause, Prevalence.
\end{abstract}

\section{Introduction}

Metabolic syndrome is a group of interrelated risk factors of metabolic origin that appear to directly advance the growth of atherosclerotic cardiovascular disease and type 2 diabetes mellitus [1,2]. It combines central obesity, hypertriglyceridemia, low high-density lipoprotein cholesterol, high blood pressure, and impaired glucose tolerance [3]. Studies showed that metabolic syndrome is associated with a threefold increased risk of coronary heart disease, myocardial infarction, and stroke [4], and a three- to fivefold increased risk of cardiovascular death $[5,6]$ even after adjustment for conventional risk factors [7]. Hence, it makes a full-fledged epidemic $[8,9]$.

Metabolic syndrome is present in $35 \%$ of the Moroccan adults [10], in $38.5 \%$ of US adults [11], $21.1 \%$ of the French population [12], and $27.8 \%$ of the Spanish population [13] (by the joint interim statement definition) [14]. Among Arab populations, the prevalence estimates are $30.0 \%$ in Tunisia [15], 21\% in Saudi Arabia [16] and 36.3\% in Jordan [17] (by the third adult treatment panel of the National Cholesterol Education Program definition) [18].

In Morocco, our previous results on the prevalence of the metabolic syndrome have expressed a high incidence of this entity among women, especially among the elderly [10]. This is, of course, the consequence of age, but the impacts of the physiological variations occurring in women (especially during menopause) are not negligible. In fact, metabolic changes and increased abdominal obesity resulting from a decrease in estrogen are one of the hypotheses explaining these results [19]. The rapid Moroccan economic growth in recent decades has made drastic changes in the lifestyle of the Moroccan population [20]. Excess energy intake and sedentary lifestyle are becoming widespread in the population, and is raising metabolic risk factors such as obesity, diabetes, and high blood pressure to the epidemic level $[21,22]$ that lead to metabolic syndrome. Moreover, the high prevalence of metabolic syndrome in postmenopausal women has been depicted in various subject areas. It has ranged from $18.3 \%$ among

\footnotetext{
${ }^{*}$ Corresponding author: $\underline{\text { bbenazzouz@gmail.com }}$
} 
premenopausal [23] to more than $60 \%$ in postmenopausal women [24].

To our knowledge, no such studies have been performed in Morocco. The purpose of this study is to determine the prevalence of metabolic syndrome and its individual components according to menopausal status in a population of Moroccan women.

\section{Materiel and Methods}

\subsection{Patients and methods}

It is a retrospective study based on the analysis of the files of 653 women consultants at the diagnosis center of Rabat during a period of 20 months from October 2010 to May 2012.

The file analyses consist of exploitation of: 1) anthropometric parameters (the age and the waist circumference which permits the evaluation of the abdominal obesity of the patient), and 2) the results of the measurement of blood pressure and the dosage of biochemical parameters (glycemia, triglyceridemia, total cholesterol and high-density lipoproteincholesterol).

To wait for an upshot of the menopause on the prevalence of the metabolic syndrome, women under and over 48.4 years has referred to as pre- and postmenopausal according to Reynolds and al [25].

\subsection{Definition of the metabolic syndrome}

Granting to the recently published joint interim statement endorsed by the International Diabetes Federation Task Force and several other international and national constitutions to define metabolic syndrome [26]. Women were considered to have metabolic syndrome if they had any three or more of the following criteria:

- Elevated waist circumference (populationand country-specific cutoffs: $\geq 94 \mathrm{~cm}$ for men and $\geq 80 \mathrm{~cm}$ for women).

- $\quad$ Elevated triglycerides $\geq 150 \mathrm{mg} / \mathrm{dL}$ (1.69 $\mathrm{mmol} / \mathrm{L})$.

- $\quad$ Reduced high density lipoprotein cholesterol (high-density lipoprotein-cholesterol) $[<40$ $\mathrm{mg} / \mathrm{dL}(1.04 \mathrm{mmol} / \mathrm{L})$ in $\mathrm{men}$, and $<50$ $\mathrm{mg} / \mathrm{dL}(1.29 \mathrm{mmol} / \mathrm{L})$ in women].

- $\quad$ Elevated blood pressure (systolic $\geq 130$ $\mathrm{mmHg}$ and/or diastolic $\geq 85 \mathrm{mmHg}$ ).

- $\quad$ Elevated fasting glucose $\geq 100 \mathrm{mg} / \mathrm{dL}$ (5.56 $\mathrm{mmol} / \mathrm{L})$.

\subsection{Statistical Analysis}

The chi-square test was performed to compare the crude prevalence rate between pre- and postmenopausal women. The analyses reported in this study were performed using the Statistical Analysis
System (SAS). P values less than 0.05 were considered statistically significant.

\section{Results}

A total of 653 women were retained in the study. The average age of the population was $52.78 \mathrm{y} \pm 12.33$. Postmenopausal women were more obese and suffer high blood glucose levels compared to those in premenopause. (Table 1).

The prevalence of metabolic syndrome in the entire women population was $40.12 \%$. Abdominal obesity was the most common abnormality $(56.81 \%)$ followed by Low High-Density Lipoprotein-cholesterol (43.34\%). Prevalence of metabolic syndrome and abdominal obesity were more common in women in postmenopause than in premenopause. (Table 2).

To explore the variation of metabolic syndrome prevalence according to menopausal status, we introduced the menopausal transition period. It was obtained from the standard deviations around the mean age of menopause in Morocco.

The prevalence of metabolic syndrome was significantly higher among women in menopausal transition period $(49.81 \%)$ compared to those in premonopause $(25.33 \%)$ and postmenopause $(38.75 \%)$ $(\mathrm{P}<0.0001)$. Women aged $49-52$ years have the highest prevalence of metabolic syndrome (62.59\%) $(\mathrm{P}<0.0001)$ (Table 3). Women during menopausal transition have a significantly higher prevalence of abdominal obesity and hypertriglyceridemia compared with those in premenopause and menopause $(\mathrm{P}<0.05)$.

In our population, $87.44 \%$ of women have at least one abnormality of metabolic syndrome. An accumulation of factors of metabolic syndrome was observed in perimenopausal women. During this period, half of women (49.81\%) have at least three metabolic syndrome risk factors (Table 4).

\section{Discussion}

The outcomes of this study indicate a high prevalence of metabolic syndrome among Moroccan women. Similar results were cited by several studies using the same definition $[10,27,28]$. Our findings also show that the prevalence of metabolic syndrome in Moroccan women has changed according to the menopausal status, becoming higher in postmenopausal women $(45.08 \%)$ than those in the premenopause $(32.96 \%)$, $(\mathrm{P}<0.05)$. This is consistent with studies conducted in Iran [23,29], India [27] and in Brazil [30]. The change in body metabolic status and the type of fat substitution in different tissues occurring with menopause is one of the theories about the incidence of metabolic syndrome during postmenopause.

In our population, postmenopausal women experienced significantly higher prevalence of abdominal obesity. This indicates that this abnormality could be the primary case of the emergence of

\footnotetext{
${ }^{*}$ Corresponding author: bbenazzouz@gmail.com
} 
metabolic syndrome in women in menopause. The issue of abdominal obesity after menopause has been shown in several studies [24,31], except for H. Ramin and al. who found no substantial dispute in the prevalence of abdominal obesity between the different menopausal status [32]. A great deal of metabolic changes in postmenopausal women are linked to the decrease in estrogen secretion and consequent accumulation of abdominal fatty tissue [19,24,28].

Table 1: Anthropometric and metabolic characteristics of the studied population.

\begin{tabular}{|l|c|c|c|c|}
\hline Parameters & $\begin{array}{c}\text { Entire population } \\
\text { (n= 653) }\end{array}$ & $\begin{array}{c}\text { Premenopausal } \\
\text { women } \\
(\mathbf{n = 2 6 7 )}\end{array}$ & $\begin{array}{c}\text { Postmenopausal } \\
\text { women } \\
\text { (n= 386) }\end{array}$ & P value \\
\hline Age (year) & $52.78 \pm 12.33$ & $41.94 \pm 6.74$ & $60.28 \pm 9.40$ & $<\mathbf{0 . 0 0 0 1 * * *}$ \\
Waist Circumference (cm) & $87.31 \pm 10.96$ & $85.64 \pm 10.21$ & $88.47 \pm 11.32$ & $\mathbf{0 . 0 0 1 1 * *}$ \\
Systolic Pressure (mm Hg) & $136.83 \pm 18.36$ & $135.85 \pm 18.49$ & $137.51 \pm 18.26$ & 0.2563 \\
Diastolic Pressure (mm Hg) & $77.11 \pm 10.88$ & $76.57 \pm 10.75$ & $77.48 \pm 10.97$ & 0.2938 \\
Glycemia (g/l) & $1.201 \pm 0.537$ & $1.149 \pm 0.499$ & $1.236 \pm 0.560$ & $\mathbf{0 . 0 4 1 8 *}$ \\
Total Cholesterol (g/l) & $2.014 \pm 0.406$ & $1.997 \pm 0.397$ & $2.026 \pm 0.413$ & 0.413 \\
High Density Lipoprotein (g/l) & $0.543 \pm 0.183$ & $0.536 \pm 0.166$ & $0.548 \pm 0.195$ & 0.4122 \\
Low Density Lipoprotein (g/l) & $1.207 \pm 0.381$ & $1.204 \pm 0.363$ & $1.209 \pm 0.393$ & 0.393 \\
Triglyceridemia (g/l) & $1.321 \pm 0.715$ & $1.285 \pm 0.657$ & $1.346 \pm 0.752$ & 0.2840 \\
\hline
\end{tabular}

Data were presented as mean \pm standard error.

Note: ${ }^{* * *} P<0.001 ;{ }^{* *} P<0.01 ;{ }^{*} P<0.05$. n: size of the group.

Table 2: Prevalence of the metabolic syndrome and its components among all studied women and by menopausal status.

\begin{tabular}{|l|l|l|l|l|}
\hline & $\begin{array}{c}\text { Total population \% } \\
(\mathbf{n = 6 5 3 )}\end{array}$ & $\begin{array}{c}\text { Premenopausal \% } \\
(\mathbf{n = 2 6 7 )}\end{array}$ & $\begin{array}{c}\text { Postmenopausal \% } \\
(\mathbf{n = 3 8 6})\end{array}$ & P value \\
\hline MetS & $40.12(262)$ & $32.96(88)$ & $45.08(174)$ & $\mathbf{0 . 0 0 1 9 * *}$ \\
MetS Components: & & & & \\
Abdominal Obesity & $56.81(371)$ & $46.82(125)$ & $63.73(246)$ & $<\mathbf{0 . 0 0 0 1 * * *}$ \\
Hypertension & $30.63(200)$ & $29.59(79)$ & $31.35(121)$ & 0.63 \\
Hyperglycemia & $19.75(129)$ & $21.72(58)$ & $18.39(71)$ & 0.29 \\
Hypertriglyceridemia & $32.01(209)$ & $29.59(79)$ & $33.68(130)$ & 0.27 \\
Low High Density & $43.34(283)$ & $42.70(114)$ & $43.78(169)$ & 0.78 \\
lipoprotein cholesterol & & & & \\
\hline
\end{tabular}

Note: ${ }^{* * *} P<0.001 ;{ }^{* *} P<0.01$. n: size of the group. MetS: Metabolic Syndrome.

Table 3: Variation in the frequency (\%) of metabolic syndrome (Table 3a) and its components (Table 3b) by menopausal status in studied women.

Table 3a

\begin{tabular}{|l|c|c|c|c|c|}
\hline Menopausal status & Age classes & n & MetS Prevalence (\%) & \multicolumn{2}{|c|}{ P value } \\
\hline Premenopause & All ages & 38 & 25.33 & & \multirow{3}{*}{$<0.0001 * * *$} \\
\hline \multirow{4}{*}{ Perimenopause } & {$[45-48]$} & 29 & 33.72 & $<0.0001 * * *$ \\
\cline { 2 - 5 } & {$[49-52]$} & 87 & 62.59 & & \\
\cline { 2 - 5 } & {$[53-55]$} & 15 & 39.47 & & \\
\cline { 2 - 5 } & All ages & 131 & 49.81 & & \\
\hline Postmenopause & All ages & 93 & 38.75 & & \\
\hline Entire population & All ages & 262 & 40.12 & & \\
\hline
\end{tabular}

Table 3b

\begin{tabular}{|l|c|c|c|c|c|}
\hline $\begin{array}{l}\text { Metabolic syndrome } \\
\text { abnormalities }\end{array}$ & $\begin{array}{c}\text { Entire } \\
\text { population }\end{array}$ & Premenopause & Perimenopause & Postmenopause & P value \\
\hline Group size & $\mathbf{6 5 3}$ & $\mathbf{1 5 0}$ & $\mathbf{2 6 3}$ & $\mathbf{2 4 0}$ & \\
\hline Abdominal obesity (\%) & 56.81 & 40.67 & 64.64 & 58.33 & $<\mathbf{0 . 0 0 0 1 * * *}$ \\
\hline Hypertension (\%) & 30.63 & 28.00 & 34.98 & 27.50 & 0.14 \\
\hline Hyperglycemia (\%) & 19.75 & 21.33 & 19.39 & 19.17 & 0.86 \\
\hline $\begin{array}{l}\text { Hypertriglyceridemia } \\
\text { (\%) }\end{array}$ & 32.01 & 26.00 & 37.64 & 29.58 & $\mathbf{0 . 0 3 1 *}$ \\
\hline $\begin{array}{l}\text { Low High-Density } \\
\text { Lipoprotein (\%) }\end{array}$ & 43.34 & 40.00 & 46.01 & 42.50 & 0.47 \\
\hline
\end{tabular}

Note: ${ }^{* * *} P<0.001 ;{ }^{*} P<0.05$. n: size of the group.

\footnotetext{
${ }^{\text {* Corresponding author: bbenazzouz@gmail.com }}$
} 
Table 4: Variation in the frequency (\%) of risk factors associated with metabolic syndrome by menopausal status in the studied population.

\begin{tabular}{|l|c|c|c|c|c|}
\hline $\begin{array}{l}\text { Number of metS } \\
\text { risk factors }\end{array}$ & $\begin{array}{c}\text { Entire } \\
\text { population } \\
(\mathbf{n = 6 5 3 )}\end{array}$ & $\begin{array}{c}\text { Premenopause } \\
(\mathbf{n = 1 5 0 )}\end{array}$ & $\begin{array}{c}\text { Perimenopause } \\
(\mathbf{n = 2 6 3 )}\end{array}$ & $\begin{array}{c}\text { Postmenopause } \\
(\mathbf{n = 2 4 0 )}\end{array}$ & P value \\
\hline One or more (\%) & 87.44 & 86.00 & 89.35 & 86.25 & 0.48 \\
\hline Two or more (\%) & 64.62 & 55.33 & 71.10 & 63.33 & $\mathbf{0 . 0 0 4 8 * *}$ \\
\hline Three or more (\%) & 40.12 & 25.33 & 49.81 & 38.75 & $<\mathbf{0 . 0 0 0 1} * * *$ \\
\hline Four or more (\%) & 14.70 & 8.67 & 20.53 & 12.08 & $\mathbf{0 . 0 0 1 7} * *$ \\
\hline
\end{tabular}

Note: ${ }^{* * *} P<0.001 ;{ }^{* *} P<0.01$.

In this study, we explored the variation in the prevalence of metabolic syndrome during perimenopausal transition. We noticed a height in the metabolic syndrome prevalence during this period (49.81\%) in comparison to $25.33 \%$ and $38.75 \%$ in premenopausal and postmenopausal women, respectively $(\mathrm{P}<0.05)$. A maximum of this prevalence is showed between 49-52 years which correspond to the first three years after the age of natural menopause in Morocco. This result refutes the theory of age as the unique main factor underlying the development of metabolic syndrome in women. In contrast, other studies have reported an intermediate prevalence between premenopausal and postmenopausal status $[24,32]$. This may partially be due to the conception of the study (age of menopause determined from the average age of natural menopause in Morocco).

Our study shows that $64.64 \%$ of women in menopausal transition have abdominal obesity (as opposed to $40.67 \%$ in premenopausal and to $58.33 \%$ in postmenopausal women $\mathrm{P}<0.0001)$. This finding confirms that this risk factor is the main factor responsible for the development of metabolic syndrome during the transition from premonopause to postmenopause. Reference [33] has shown that abdominal obesity was the most common abnormality during the passage to postmenopause [33]. Natural menopause is associated with an increase in abdominal obesity $[23,34,35]$. Thus, it seems thereby necessary to take a weight loss strategy to prevent metabolic syndrome and its cardiovascular complications. Likewise, $89.35 \%$ of women in the perimenopause have at least one metabolic syndrome abnormalities and half of them $(49.81 \%)$ have three or more metabolic syndrome risk factors. This suggests that this menopausal status has a dual risk for the women health: 1) A tangible cardiovascular risk, represented by the high prevalence of metabolic syndrome. 2) A further risk bound to the large number of women with different metabolic syndrome abnormalities candidates to develop this entity during the next years.

The exploitation of menopause by median age rather than a measure in our sample may limit generalization of the results of this study.

\section{Conclusion}

\footnotetext{
* Corresponding author: bbenazzouz@gmail.com
}

Metabolic syndrome has become a significant health problem in Morocco [10]. Our study showed a high prevalence of this entity among Moroccan women, especially in menopausal transition and postmenopause. Abdominal obesity, linked up with metabolic changes, was the most common risk factor underlying the development of metabolic syndrome in women after menopause. All attempts should be constructed to prevent weight gain in women by lifestyle modification. This can decrease the prevalence of metabolic syndrome and its complications as type 2 diabetes and cardiovascular diseases.

\section{References}

[1] S. Jesmin, R. Islam, S. Islam, S. Mia, S. N. Sultana, S. Zaedi, N. Yamaguchi, Y. Iwashima, M. Hiroe, T. Watanabe. Comprehensive assessment of metabolic syndrome among Rural Bangladeshi Women. BMC Public Health, 12-49 (2012)

[2] P. T. Katzmarzyk, T. S. Church, S. N. Blair, Cardiorespiratory fitness attenuates the effects of the metabolic syndrome on all cause and cardiovascular disease mortality in men. Arch Intern Med. 164:1092-1097 (2004)

[3] G. M. Reaven. Banting lecture 1988: role of insulin resistance in human disease. Diabetes. 37:1595-1607 (1988)

[4] B. Isomaa, P. Almgren, T. Tuomi, B. Forsén, K. Lahti, M. Nissén, M. R. Taskinen, L. Groop, Cardiovascular morbidity and mortality associated with the metabolic syndrome. Diabetes Care. 24:683-689 (2001)

[5] S. M. Haffner, R. A. Valdez, H. P. Hazuda, B. D. Mitchell, P. A. Morales, M. P. Stern. Prospective analysis of the insulin resistance syndrome (syndrome X). Diabetes. 41:715-722 (1992)

[6] L. Mykkänen, J. Kuusisto, K. Pyörälä, M. Laakso. Cardiovascular disease risk factors as predictors of type 2 (non-insulindependent) diabetes mellitus in elderly subjects. Diabetologia. 36:553-559 (1993)

[7] H. M. Lakka, D. E. Laaksonen, T. A. Lakka, L. K. Niskanen, E. Kumpusalo, J. Tuomilehto, J. T. Salonen. The metabolic syndrome and total and cardiovascular disease mortality in middle-aged men. JAMA. 288:2709-2716 (2002) 
[8] D. J. Kereiakes, J. T. Willerson. Metabolic syndrome epidemic. Circulation. 108:1552-1553 (2003)

[9] S. M. Grundy. Metabolic syndrome pandemic. Arterioscler Thromb Vasc Biol. 28:629-636 (2008)

[10] O. El Brini, O. Akhouayri, A. Gamal, A. Mesfioui, B. Benazzouz. Prevalence of metabolic syndrome and its components based on a harmonious definition among adults in Morocco. Diabetes Metab Syndr Obes. 31;7-341-6 (2014)

[11]E. S. Ford, C. Li, G. Zhao. Prevalence and correlates of metabolic syndrome based on a harmonious definition among adults in the US. J Diabetes. 2:180-193 (2010)

[12] M. Vernay, B. Salanave, C. de Peretti, C. Druet, A. Malon, V. Deschamps, S. Hercberg, K. Castetbon. Metabolic syndrome and socioeconomic status in France: The French Nutrition and Health Survey (ENNS, 2006-2007). Int J Public Health. 58:855864 (2013)

[13] A. Corbatón-Anchuelo, M. T. Martínez-Larrad, C. Fernández-Pérez, S. Vega-Quiroga, J. M. IbarraRueda, S. M. Segovia. Insulin Resistance Study Group, Metabolic syndrome, adiponectin, and cardiovascular risk in Spain (the Segovia study): impact of consensus societies criteria, Metab Syndr Relat Disord. 11(5):309-318 (2013)

[14] K. G. Alberti, R. H. Eckel, S. M. Grundy, P. Z. Zimmet, J. I. Cleeman, K. A. Donato, J. C. Fruchart, W. P. James, C. M. Loria, S. C. Jr Smith. International Diabetes Federation Task Force on Epidemiology and Prevention; Hational Heart, Lung, and Blood Institute; American Heart Association; World Heart Federation; International Atherosclerosis Society; and International Association for the Study of Obesity, Harmonizing the metabolic syndrome: a joint interim statement of the International Diabetes Federation Task Force on Epidemiology and Prevention; National Heart, Lung, and Blood Institute; American Heart Association; World Heart Federation; International Atherosclerosis Society; and International Association for the Study of Obesity. Circulation. 120:1640-1645 (2009)

[15]H. Belfki, S. Ben Ali, H. Aounallah-Skhiri, P. Traissac, S. Bougatef, B. Maire, F. Delpeuch, N. Achour, H. Ben Romdhane. Prevalence and determinants of the metabolic syndrome among Tunisian adults: results of the Transition and Health Impact in North Africa (TAHINA) project. Public Health Nutr. 16:582-590 (2013)

[16]A. M. Alzahrani, A. M. Karawagh, F. M. Alshahrani, T. A. Naser, A. A. Ahmed, E. H. Alsharef, Prevalence and predictors of metabolic syndrome among healthy Saudi Adults. $\mathrm{Br} \mathrm{J}$ Diabetes Vasc Dis. 12:78-80 (2012)

[17] Y. Khader, A. Bateiha, M. El-Khateeb, A. AlShaikh, K. Ajlouni, High prevalence of the metabolic syndrome among Northern Jordanians. J Diabetes Complications. 21:214-219 (2007)

[18] National Cholesterol Education Program (NCEP) Expert Panel on Detection, Evaluation, and Treatment of High Blood Cholesterol in Adults (Adult Treatment Panel III), Third report of the National Cholesterol Education Program (NCEP) expert panel on detection, evaluation, and treatment of high blood cholesterol in adults (Adult Treatment Panel III) final report. Circulation. 106(25):3143-3421 (2002)

[19]R. A. Lobo. Metabolic syndrome after menopause and the role of hormones. Maturitas. 60(1):10-18 (2008)

[20] S. Benjelloun, Nutrition transition in Morocco. Public Health Nutr. 5:135-140 (2002)

[21] M. El ayachi, M. Mziwira, S. Vincent, C. Defoort, H. Portugal, D. Lairon, R. Belahsen, Lipoprotein profile and prevalence of cardiovascular risk factors in urban Moroccan women. Eur J Clin Nutr. 59:1379-1386 (2005)

[22]F. Essiarab, H. Taki, A. El Malki, M. Hassar, R. Saile, N. Ghalim. Cardiovascular risk factors prevalence in a Moroccan population. Eur J Sci Res. 49(4):581-589 (2011)

[23] E. Radina, E. Alireza, N. Manouchehr, Menopause is an independent predictor of metabolic syndrome in Iranian women. Maturitas. 65: 262-266 (2010)

[24] E. Ainy, P. Mirmiran, S. Zahedi Asl, F. Azizi, Prevalence of metabolic syndrome during menopausal transition Tehranian women: Tehran Lipid and Glucose Study (TLGS). Maturitas. 58:150-155 (2007)

[25] R. F. Reynolds, C. M. Obermeyer. Correlates of the age at natural menopause in Morocco, Ann Hum Biol. 30(1):97-108 (2003)

[26] K. G. Alberti, R. H. Eckel, S. M. Grundy, P. Z. Zimmet, J. I. Cleeman, K. A. Donato, J. C. Fruchart, W. P. James, C. M. Loria, S. C. Jr Smith. International Diabetes Federation Task Force on Epidemiology and Prevention; Hational Heart, Lung, and Blood Institute; American Heart Association; World Heart Federation; International Atherosclerosis Society; and International Association for the Study of Obesity, Atherosclerosis Society; and International Association for the Study of Obesity and Blood Institute; American Heart Association; World Heart Federation; International Diabetes Federation Task Force on Epidemiology and Prevention; National Heart, Lung, Harmonizing the Metabolic Syndrome: A Joint Interim Statement of the International. Circulation. 120:1640-1645 (2009)

[27]P. Shefali, S. Manisha, A. Shubhada, J. Jayashree, G. Priti, C. P. Prakasam, V. Rama. Menopause, and metabolic syndrome: A study of 498 urban women from western India. J. Midlife. 1(2): 63-69 (2010)

\footnotetext{
${ }^{*}$ Corresponding author: bbenazzouz@gmail.com
} 
[28] F. Kow Nanse Arthur, M. Adu-Frimpong, J. OseiYeboah, F. Obu Mensah, L. Owusu. The prevalence of metabolic syndrome and its predominant components among pre-and postmenopausal Ghanaian women. BMC Research Notes. 6:446 (2013)

[29] E. Pantea, F. Hossein, H. Ramin, G. Maryam, B. Fatemeh, L. Bagher. Metabolic syndrome and menopause: A population-based study. Diabetes \& Metabolic Syndrome: Clinical Research \& Reviews. 4:5-9 (2010)

[30] J. A. Figueiredo Neto, E. D. Figuerêdo, J. B. Barbosa, Fde F. Barbosa, G. R. Costa, V. J. Nina, R. V. Nina. Metabolic syndrome and menopause: Cross-sectional study in gynecology clinic. Arq Bras Cardiol. 95:339-345 (2010)

[31] H. M. Kim, J. Park, S. Y. Ryu, J. Kim, The effect of menopause on the metabolic syndrome among Korean women: The Korean National Health and Nutrition Survey 2001, Diabetes care. 30:701-706 (2007)

[32] H. Ramin, S. Masoumeh, T. Mouhammad, R. Katayoun, M. Noushin, S. Nizal. Metabolic syndrome in menopausal transition: Isfahan Healty Heart Program, a population-based study. Diabetology \& Metabolic syndrome. 2:59 (2010)

[33] V. R. Mesch, L. E. Boero, N. O. Siseles, M .Royer, M. Prada, F. Sayegh, L. Schreier, H. J. Benencia, G. A. Berg. Metabolic syndrome throughout the menopausal transition: influence of age and menopausal status, Climacteric. 1:40-8 (2006)

[34]E. T. Poehlman, M. J. Toth, A. W. Gardner. Changes in energy balance and body composition at menopause: a controlled longitudinal study. Ann Intern Med. 123:673-675 (1995)

[35]M. J. Toth, A. Tchernof, C. K. Sites, E. T. Poehlman. Effect of menopausal status on body composition and abdominal fat distribution. Int $\mathrm{J}$ Obes Relat Metab Disord. 24:226-231 (2000)

\footnotetext{
*Corresponding author: bbenazzouz@gmail.com
} 